\title{
EL MARKETING EN LA ECONOMIA INFORMAL PERUANA
}

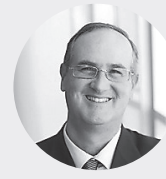

\author{
JAMES H. LEIGH \\ - Profesor de Brand and Product Management \\ Carrera de Administración y Marketing \\ Facultad de Negocios, UPC
}

El Perú es una de las economías más informales del mundo. Específicamente, somos el sexto país con mayor informalidad económica: el 61\% de nuestro PBI es informal y el 90\% de las empresas son informales (Radio Programas del Perú, 2015).

Estas cifras son contundentes e impactantes. Sin embargo, habría que preguntarse ¿qué tanto conocemos de este tipo de economía? y, precisamente, ¿cómo el marketing influye en la economía informal? El tema es muy serio y de grandes dimensiones; y es poco abordado y conocido por empresas, ejecutivos y el mismo Estado. Es vital que para cualquier empresa que es un actor en actividades comerciales, debiera entender lo importante que es este tema y sus aspectos y características más importantes. Es más, pienso que conociendo más este tema, nos permitirá entender las características de la mayoría de mercados peruanos y a los mismos peruanos como consumidores.

Primero, entendamos qué es la informalidad; cuáles son sus causas; cómo impactan e influyen en la sociedad; qué impacto puede tener sobre los mercados y la economía. Según Loayza (2015) sobre la informalidad en el Perú, "está constituida por el conjunto de empresas, trabajadores y actividades que operan fuera de los marcos legales y normativos que rigen la actividad económica"(p. 44). Esta puede originarse por la presencia de reglamentos, trámites, procesos, tributarios, burocráticos, legales en exceso que, además, está ligado a muchos elementos que la identifican. Los bajos niveles educativos, la población joven, la población rural, la corrupción, las estructuras productivas primarias, son algunos de estos elementos, circundados por, además, una débil capacidad de supervisión y ejecución del Estado.

Según Arellano (1994), sabemos que, al ayudar a subsistir a las millones de familias que migraron del campo a la ciudad, la informalidad permitió el desarrollo de las nuevas clases medias emergentes del país. Sabemos también que, al permitirles acceder a la propiedad de sus empresas y viviendas, ayudó a parar las ideas violentistas de la época. La paradoja es que esa misma informalidad

es hoy un freno para el desarrollo económico y una traba para la consolidación de la democracia del país, lo que hace urgente generar acciones para disminuirla.

Arellano (1994), asimismo, menciona que el 40\% del sector informal está en la venta al menudeo. Por otro lado se menciona que las tácticas de los informales se basan en precios bajos (bajos costos), alta movilidad (flexibilidad al cambio/ adaptabilidad), y eficiencia (bajo riesgo, promoción).

\section{...EL BCR, EN UN ESTUDIO SOBRE EL EFECTO QUE TIENE LA INFORMALIDAD SOBRE EL CRECIMIENTO ECONÓMICO, MUESTRA QUE UN INCREMENTO EN LA INFORMALIDAD GENERA UNA DISMINUCIÓN EN EL CRECIMIENTO ECONÓMICO...}

Por otro lado, Schneider y Enste (2000), en un estudio sobre el efecto que tiene la informalidad sobre el crecimiento económico, muestra que un incremento en la informalidad genera una disminución en el crecimiento económico, la que, según el índice de Schneider, podría llegar a reducir hasta en 2 puntos porcentuales el PBI per cápita. Este resultado es contundente, toda vez que muestra causalidad estadística y correlación negativa entre la informalidad y el crecimiento. Debemos accionar en el más pronto posible tiempo para mejorar.

El Marketing busca crear valor para los clientes donde se busca generar un fidelización y relaciones a largo plazo. Estoy seguro y convencido que en una economía informal el marketing existe y se desarrolla de una forma determinada, donde sabemos que los que participan en un mercado informal tienen la facilidad para ser informales. El agente económico informal busca generar valor en sus acciones comerciales, para lo que, al margen 
de la informalidad en la que opera, debe tener su estrategia de precio, una promoción y distribución de lo que vende, inclusive apelando a medios digitales.

Por lo anterior, es el momento de iniciar un mayor entendimiento del marketing en la economía informal; aceptándola y tratando de entender ese desarrollo de clases medias profundamente para que podamos capitalizar nuestros propósitos empresariales y así desarrollar un mejor sentido de nuestro país, para entender más a nuestro Perú, y por nuestro bienestar.

\section{REFERENCIAS}

Arellano, R. (1994). Informal-underground retailers in less-developed countries: An exploratory research from a marketing point of view. Journal of Macromarketing, 14(2), 21-35.

Loayza, N. (2015). Causas y consecuencias de la informalidad en el Perú. En Estudios Económicos (págs. 43-64). Lima, Perú: Banco Central de Reserva del Perú.

Radio Programas del Perú. (2015). Lima. Obtenido de Radio Programas del Perú: http://rpp.pe/lima/actualidad/ noticia-360-peru-es-uno-de-los-paises-mas-informales-delmundo-noticia-762514

SBS. (2015). Obtenido de Superintendencia de Banca, Seguros y AFP: http://www.sbs.gob.pe/app/stats/tc-cv.asp

Schneider, F., \& Enste, D. (2000). Shadow economies: size, causes and consequences. Journal of Economic Literature, 38(1), 77-114. 